\title{
Deambulações situacionistas em Bom Retiro 958 metros
}

\author{
Luís Fabiano Oliveira \\ Silvia Balestreri ${ }^{1}$
}

À medida que a necessidade se encontra socialmente sonhada, o sonho se torna necessário. O espetáculo é o sonho mau da sociedade moderna aprisionada, que só expressa afinal o seu desejo de dormir. O espetáculo é o guarda desse sono. (DEBORD, 1997, p.19)

\section{Resumo}

O artigo estabelece aproximações entre o movimento de vanguarda europeu Internacional Situacionista, através de reflexões sobre as suas ideias e práticas, com a dramaturgia e encenação apresentadas pelo grupo paulista Teatro da Vertigem no espetáculo Bom Retiro 958 metros. À prática das derivas como dispositivo de criação juntam-se outros aspectos comuns com as propostas situacionistas, observados na própria apresentação do espetáculo.

Palavras-chave: Situacionismo; Teatro da Vertigem; Derivas.

\section{Abstract}

The article makes an approach between the European avant-garde movement Situationist International and the dramaturgy and staging presented by the group Teatro da Vertigem, from São Paulo, Brazil, in Bom Retiro 958 metros. The authors stress similarities between Vertigem's new theatrical work and some situationist experiments and ideas, laying emphasis on the use of drift (dérive) as a device for creating scenes.

Keywords: Situationism; Teatro da Vertigem; Drifts.

Sob o lema de "construção de situações" é fundada, em julho de 1957, a Internacional Situacionista, cujo principal teórico é o autor do conhecido livro $A$ Sociedade do Espetáculo, Guy Debord. Reunindo principalmente poetas, arquitetos, cineastas e artistas plásticos, o movimento tem um propósito bem claro: provocar uma revolução na vida cotidiana contra a alienação e a passividade da sociedade, através de uma

\footnotetext{
${ }^{1}$ Luís Fabiano Oliveira é graduando em Direção Teatral no Departamento de Arte Dramática da Universidade Federal do Rio Grande do Sul (UFRGS), bolsista PIBIC-CNPq do Projeto Teatro e Produção de Subjetividades: Exercícios Micropolíticos, no qual atua desde agosto de 2009.

Silvia Balestreri é Professora Adjunta do Departamento de Arte Dramática e do Programa de Pós-Graduação em Artes Cênicas da UFRGS, coordenadora do Projeto Teatro e Produção de Subjetividades: Exercícios Micropolíticos, que tem como um de seus eixos estudar as possibilidades de um Teatro Sem-Espetáculo (Carmelo Bene) na Sociedade do Espetáculo (Guy Debord).
} 
crítica unitária² à sociedade capitalista e ações que mobilizem as pessoas a se engajarem em um movimento para abolir o Mercado e o Estado.

O urbanismo e a arquitetura foram temas de muitos artigos de membros da Internacional Situacionista (IS), por entenderem que as práticas e intervenções no espaço urbano têm como fonte a crítica da vida cotidiana. Em documento publicado quando de sua fundação, os situacionistas afirmam que "nossa perspectiva de ação tende, em última análise, à concepção de um urbanismo unitário" (DEBORD, 2007, p. 48-49). As derivas como prática da psicogeografia defendem as perambulações ao acaso pela cidade, estimulando reinterpretações do espaço com base na experiência vivida. Neste mesmo documento fundacional, pode-se ler: "a construção de situações começa pela destruição da moderna noção de espetáculo" (DEBORD, 2007, p. 56). Há aí uma relação entre a noção de espetáculo associada à não intervenção, ou seja, como manutenção da alienação. Os situacionistas irão combater esta visão de arte fundamentada na contemplação de imagens, que representaria uma forma de viver pelo não-vivido.

Ao completar vinte anos de existência, o grupo paulista Teatro da Vertigem celebra com a realização de uma grande deambulação coletiva pelo bairro do Bom Retiro, localizado na região central de São Paulo. Após ocupar espaços aparentemente tão díspares como uma igreja (O Paraíso Perdido), um hospital (O Livro de Jó), uma prisão (Apocalipse 1,11), o rio Tietê (BR 3) ou os altos de um prédio na Av. Paulista (Kastelo), a escolha agora recaiu sobre três locais que se complementam e que constituem um caminho percorrido ao longo das duas horas de Bom Retiro 958 metros: um centro comercial, logradouros públicos e um instituto cultural abandonado. Ao conduzir o espectador por estes ambientes povoados por personagens criadas, dentre outros dispositivos, a partir de derivas realizadas no próprio bairro, o Vertigem apresenta temas essenciais da trajetória do grupo: crítica à sociedade de consumo e à mercantilização da cultura, apropriações afetivas, fluidas e não compartimentadas dos espaços urbanos, construção de linhas de fuga que rompem com o normatizado. A aproximação com os situacionistas que, a princípio, se daria pela utilização das

\footnotetext{
2 "Por crítica unitária entendemos uma crítica dirigida globalmente contra todas as zonas geográficas onde se instalaram diversas formas de poderes socioeconômicos separados, e que se pronuncia também globalmente contra todos os aspectos da vida." (INTERNACIONAL SITUACIONISTA, 1967./Acesso 15/10/2012) Tal afirmação remete à critica contida posteriormente no livro Sociedade do Espetáculo contra o espetacular concentrado (capitalismo burocrático) e espetacular difuso (capitalismo moderno), quando Debord não faz distinção entre um e outro em relação às consequências contra os aspectos da vida.
} 
derivas como um dos dispositivos para a criação cênica, ao nosso ver, amplia-se e contamina todo o espetáculo ao ponto de "borrar" as fronteiras entre arte e cotidiano.

Um dos principais temas da Internacional Situacionista (IS) foi o de construir uma nova concepção para a cidade, que era vista, em sua estrutura funcionalista e hierarquizante, como uma prisão mental e física do espetáculo. Segundo definições extraídas dos primeiros números da revista $I S$, publicados no final da década de 50 do século passado, a psicogeografia (estudo dos efeitos exatos do meio geográfico, conscientemente planejado ou não, que agem diretamente sobre o comportamento afetivo dos indivíduos), o urbanismo unitário (uso conjunto das artes e das técnicas como meio que concorre para uma composição integral do meio) e as derivas (uma ou várias pessoas que se lançam à deriva renunciam, durante um tempo mais ou menos longo, aos motivos para deslocar-se ou atuar normalmente em suas relações, trabalhos e entretenimentos próprios de si, para deixar-se levar pelas solicitações do terreno e os encontros que a ele correspondem) eram as proposições para se encontrarem novas formas de se relacionar na e com a cidade. Quando da fundação da IS, em 1957, os processos de reconstrução de uma Europa arrasada pela guerra se constituíram como projetos de publicidade ideológica. A atuação do Teatro da Vertigem em vários locais da cidade de São Paulo, também proporcionam novas possibilidades de relacionamento com o espaço urbano. No Bom Retiro, por exemplo, as projeções afetivas do antigo bairro (que surgem quando da aparição de uma noiva perdida no tempo-espaço, sempre postada acima de marquises ou muros, em um plano superior ao da realidade) apontam para algo que se perdeu, em um tempo em que aconteciam reuniões sociais ou as prostitutas se revoltavam e se mobilizavam para protestar; as lojas, em grande quantidade e quase nenhuma diversidade, estão sempre fechadas para a consumidora ávida por novidades, apesar de ela não saber quais são estas ou nem vir a possuir a faculdade de identificá-las; o espaço do Instituto Cultural Israelita Brasileiro (ICIB) é higienizado para que possa ser transferido à iniciativa privada, provavelmente para transformar-se em mais um centro comercial.

A escolha do bairro, segundo atores e diretor, como tema para o novo espetáculo, surgiu por duas questões que se atravessam: primeiro, porque o Bom Retiro é um dos mais antigos bairros da capital paulista e notabilizou-se, ao longo dos anos, por receber comunidades de imigrantes (primeiro, os judeus; após, os coreanos e, por fim, e de forma muitas vezes clandestina, os bolivianos), vindo a sofrer mudanças que 
modificaram sensivelmente a constituição de uma memória coletiva naquela comunidade. Segundo, porque ali o Vertigem concebeu a última parte da Trilogia Bíblica, Apocalipse 1,11, e criaram-se relações afetivas entre os integrantes do grupo ao longo dos meses de criação do trabalho. Antônio Araújo observa:

Em nossas heterotopias particulares, vislumbramos a produção de uma cena-conhecimento que possa, talvez, ser capaz de modificar a minha relação comigo mesmo, com meus parceiros de criação, com a cidade onde moro e, quem sabe, auxiliar a desestabilizar percepções, anestesiamentos e visões sobre essa mesma cidade, de experimentá-la diferentemente. (ARAÚJO, 2012, p. 113)

Tivemos a oportunidade, ao longo do ano de 2011, de conversar em duas oportunidades com integrantes do grupo ${ }^{3}$. O foco destes encontros era a utilização das derivas como dispositivo para a criação cênica, visto serem os Situacionistas objeto de nossa pesquisa sobre o espetáculo e o sem-espetáculo. A primeira entrevista realizada com os atores Luciana Schwinden e Roberto Audio, com o iluminador Guilherme Bonfanti e com a co-diretora Eliana Monteiro, quando o grupo já havia realizado diversas deambulações pelo Bom Retiro, mostrou-nos o quanto as percepções sobre o bairro haviam sido ampliadas ou modificadas. "As derivas nos mostraram um outro Bom Retiro, que não nos era visível na superficialidade. Possivelmente estas descobertas entrarão na dramaturgia", relatou na ocasião Roberto Audio.

Para os Situacionistas, todos nos submetemos ao meio e aos padrões de comportamento por eles gerados. A forma como nos relacionamos em determinado espaço, tomando aqui o caso de um bairro específico, dá-se de maneira hierarquizada, compatível com nossas atribuições sociais e profissionais pré-determinadas, evitando ao máximo a possibilidade de intervenções do acaso que nos desviem de nossas funções cidadãs. A psicogeografia e o urbanismo unitário, além de seu caráter crítico, propõem justamente esta possibilidade de uma nova abordagem do meio, de novas formas de relacionamento, de construção de situações. As percepções de que algo está diferente na paisagem já tão conhecida, estranhamento gerado com as derivas (ocasião em que os integrantes do Vertigem deixaram de se relacionar com o Bom Retiro de forma funcional e se deixaram perder pelo que o acaso propunha), fez com que o grupo, além de produzir material para futuras improvisações que resultariam em

\footnotetext{
${ }^{3}$ Foi realizada uma entrevista coletiva com Luciana Schwinden (atriz), Roberto Audio (ator), Eliana Monteiro (codiretora) e Guilherme Bonfanti (iluminador), em 23/05/2011, no Hotel Plaza Porto Alegre, durante a realização do VI SESC Palco Giratório; e uma entrevista com Antônio Araújo (diretor), em 06/09/2011, na Universidade Federal do Rio Grande do Sul, durante a realização da VI Reunião Científica da ABRACE.
} 
um espetáculo, criasse novas formas de afeto a partir de novos modos de observação. O que surge em cena, ao se analisar a própria estrutura do espetáculo (com suas linhas de personagens fragmentadas, aparentemente desconexas, mas que se tocam continuadamente), de forma lúdica e ressignificada, não é o resultado de um processo, mas uma permanente deriva que, em alguns momentos, possibilita descobertas e embaralha as posições hierárquicas de artistas e espectadores.

Uma das principais críticas dos Situacionistas à obra de arte de seu tempo residia em seu caráter apassivador, isto é, em gerar no espectador uma capacidade meramente contemplativa em relação à produção do artista. No Informe sobre a construção de situações e sobre as condições da organização e a ação da tendência situacionista internacional, documento fundacional da Internacional Situacionista, podemos ler que:

A construção de situações começa pela destruição da moderna noção de espetáculo. É fácil ver até que ponto o próprio princípio do espetáculo (a não intervenção) liga-se à alienação do velho mundo. Por outro lado vemos como as investigações revolucionárias mais válidas na cultura vêm rompendo com a identificação psicológica do espectador com o herói, visando arrastá-lo à ação, e despertar suas capacidades de subverter sua própria vida. A situação é feita para ser vivida por seus construtores. O papel do "Público", se não passivo pelo menos de mero figurante, deve ir diminuindo, na medida em que aumentaremos a quantidade daqueles que em vez de serem chamados de atores, serão chamados de vivenciadores, um sentido novo deste termo. (DEBORD, 2007, p. 56-57)

A segunda entrevista foi realizada com o diretor Antônio Araújo após o término das derivas como dispositivo de criação, quando o grupo já se encontrava em sala de ensaios relacionando-se com o material coletado nas ruas do bairro. $\mathrm{Na}$ ocasião, ele nos contou que "não houve interesse em ser fiel aos situacionistas ou ao que Debord escreveu" (ARAÚJO, 2012a). As derivas haviam possibilitado ao grupo uma série de descobertas em relação ao cotidiano do Bom Retiro, como, por exemplo, o grande número de ateliês clandestinos, compostos em sua totalidade por costureiras bolivianas, e o contraste que podia ser observado nas ruas do bairro durante o dia e a noite. No primeiro caso, um intenso movimento de pessoas, devido ao grande número de lojas de confecções existentes, espalhadas pelos logradouros ou concentradas em número significativo de modernos centros comerciais; no segundo momento, uma cidade-fantasma habitada por raros transeuntes, seguranças das lojas, papeleiros que recolhem resíduos produzidos pelas lojas e ateliês ao longo do dia e onde a maior concentração de pessoas fica restrita a áreas conhecidas como "Cracolândia". Em processo inicial de construção da dramaturgia, Antônio Araújo falou sobre dispositivos que criou para as derivas: 
O dispositivo para uma deriva que eu fiz em uma noite era caminhar na direção onde houvesse mais sacos de lixos acumulados nas calçadas. Isso me levou a perceber uma enorme quantidade de retalhos que eram descartados pelas várias oficinas de costura do bairro. Estes retalhos entraram como um elemento constituidor da dramaturgia do espetáculo, a partir da deriva que realizei. (Entrevista, 06/09/2011)

Em palestra no Programa de Pós-Graduação em Artes Cênicas da Universidade Federal do Rio Grande do Sul, logo após a estreia, Antônio Araújo reiterou sua intenção de não associar o espetáculo a uma filiação situacionista: "Não foi apenas pelas derivas que minha visão sobre o bairro foi se modificando, lançamos mão de vários elementos, um deles foi a deriva”, destacou (ARAÚJO, 2012a).

Podem-se identificar ecos ou ressonâncias das ideias ou práticas situacionistas na cena contemporânea, mas raramente de forma assumida como foi o caso do Teatro da Vertigem no processo de criação de seu último espetáculo. De forma recorrente pode ser percebida uma aproximação com as ideias situacionistas, quando se procura realizar uma crítica aos veículos de comunicação de massa. A crítica ao fetichismo da imagem, realizada por Guy Debord a partir da concepção do fetichismo da mercadoria de Marx, sofre com avaliações apressadas que buscam rotular os situacionistas como teóricos da comunicação. Nosso desejo, após a realização das entrevistas e de assistir a este relato do processo, era o de tentar encontrar no espetáculo o que poderia ser resultante das derivas, visto que a identificação de práticas situacionistas na cena contemporânea é um dos objetos de estudo da pesquisa em curso.

Bom Retiro 958 metros faz uma crítica do espetáculo "por dentro" do espetáculo, lembrando-nos do pluriartista italiano Carmelo Bene, conhecido pelo seu "sem-espetáculo", mas que apresentava suas montagens nos principais teatros da Europa, como no Scala de Milão, por exemplo. O desfile dos catadores em um dos principais cruzamentos de tráfego do bairro, ou a cena com as manequins cantoras no corredor do Lombroso Fashion Mall, não têm apenas um efeito paródico ou irônico, visto que as intervenções do terrorista poético também apresentam um caráter espetacular. O que está em jogo aqui é mais do que uma escolha estética, e sim toda uma reflexão ativa sobre a sociedade de consumo e a mercantilização da cultura. A citação de uma das passagens mais famosas da Sociedade do Espetáculo, quando do ataque terrorista bem sucedido à estação da Rádio Infinita, apenas reforça algo que atravessa todo o espetáculo: estamos diante de uma obra situacionista, mesmo que o próprio Guy 
Debord fosse ou os integrantes do Vertigem possivelmente sejam os primeiros a não reconhecerem esta aliança.

A proposição de que os espectadores façam suas próprias derivas inicia quando, na retirada do ingresso, é entregue um mapa do bairro. O espetáculo inicia na rua, em frente ao centro comercial, e termina também na rua, em frente ao Instituto Cultural Israelita Brasileiro. Nas duas noites a que assistimos, pequenas mudanças vão sendo introduzidas à dramaturgia, ora pela atuação dos espectadores, ora pelos pedestres, motoristas ou espectadores não previstos, que, em alguns casos, confundem-se com os atores. O papeleiro que passa ao seu lado assistindo à cena que está acontecendo no alto de uma marquise é do elenco? As duas senhoras que param em frente ao ICIB e, ao ler a faixa de "Passa-se este ponto", começam a conversar animadamente: "Será que alguém vai alugar este prédio?" "Já estava na hora de reformar isto aquil." Elas fazem parte do grupo, são mesmo moradoras do Bom Retiro? No encontro de três ruas, logo após uma cena impactante de luta corporal entre duas prostitutas, o público não sabe para onde olhar, perdido que fica entre uma cena que não acabou devido à reação dos motoristas e outra que já inicia no alto de um prédio. Um motorista grita e puxa o foco: "Será que não vão deixar eu passar?." Assistir ao espetáculo pela segunda vez não dilui esta aproximação entre ficção e cotidiano que se trata, por vezes, de uma fusão. Aqui aparece algo novo na trajetória do grupo. Se as deambulações pelos espaços sempre foram uma constante, antes a divisão entre espaço cênico e plateia era muito mais nítida, mesmo que a distância entre eles fosse reduzida. No Bom Retiro, especialmente nas cenas da rua, esta (con)fusão não prejudica qualquer efeito de teatralidade; ao contrário, amplifica-o, gerando no espectador a possibilidade de leituras que ampliam sua capacidade reflexiva. Como afirma Féral sobre a performatividade:

\footnotetext{
A teatralidade nunca desapareceu verdadeiramente do processo, ela permanece como enquadramento indispensável. É ela que torna visível aquilo que se oferece ao olhar. Na ausência deste quadro estaríamos na performatividade pura e então absorvidos pela ação, como no real sem distância crítica. (...) Toda ação performativa lança mão da teatralidade. É ela que dá sua dimensão estética (FÉRAL, 2012, pp. 84-85).
}

Apesar de existir certa fusão entre ficção e real nas cenas de rua, transparece, no trabalho, um desejo de manter certo enquadramento do espectador, mantendo-o na condição de espectador, por mais que se "borrem" fronteiras. $\mathrm{O}$ agradecimento final de todos os atores está neste contexto - por mais pessimista e duro tudo o que está sendo mostrado, isto é um espetáculo. A questão que também me parece que existe 
aqui é como criticar este espetáculo "por dentro", o que era uma intenção da primeira fase situacionista (até o início da década de 60, quando se decide expulsar qualquer artista dos quadros da IS).

Ao retornarmos ao bairro no dia seguinte à primeira apresentação, surgiu o desejo de conversarmos com funcionários do Lombroso Fashion Mall, para esclarecer se sabiam que havia uma peça teatral ocorrendo ali quase todas as noites, se haviam assistido a alguma das apresentações e, por fim, se teriam algo a dizer sobre o espetáculo. Ao visitarmos mais de dez lojas e falarmos com aproximadamente 80 funcionárias, encontramos uma funcionária que havia assistido à parte que ocorre dentro do centro comercial. Depois de conversarmos um pouco com ela percebemos que, mais do que falar sobre atuações, utilização do espaço, figurinos ou cenografia, o que lhe havia chamado mais a atenção estava relacionado diretamente aos temas da peça e suas possíveis implicações comerciais.

Eu falei para nossa gerente questionar a administração do Lombroso do porquê desta peça aqui dentro. Quando eu ouvi falar que iam contar uma história sobre a moda do Bom Retiro, fiquei bem feliz, imaginei que iriam mostrar como as lojas são bonitas, tudo o que tem para se comprar aqui. (Funcionária de uma loja de roupas femininas do Lombroso Fashion Mall, 28/set/2012)

Pode-se questionar o porquê de se tentar estabelecer uma aliança entre o Teatro da Vertigem e um movimento europeu de vanguarda da segunda metade do século $X X$, como se arrisca neste artigo. A necessidade de se encontrarem rótulos que ajudem a categorizar ou compartimentar experiências certamente não é o aspecto a ser priorizado. Importa, como escreve Antônio Araújo, "a pesquisa como um dispositivo de criação e o artista como um criador de dispositivos de pesquisa" (ARAÚJO, 2012, p. 107) ou, como propôs Guy Debord, "temos que tentar construir situações, ou seja, ambientes coletivos, um conjunto de impressões que determinam a qualidade de um momento". (DEBORD, 1957/2007, p. 56). A construção de eixos, aproximações e alianças podem ser dispositivos para a criação de reflexões sobre dispositivos de pesquisas, mas também para práticas, para experimentações, para o espetáculo, para o sem-espetáculo...

\section{Referências}

ARAÚJO, Antônio. A cena como processo de conhecimento. In: RAMOS, Luiz Fernando (org.). Arte e ciência: abismo de rosas. São Paulo: ABRACE, 2012. pp.105-113.

ARAÚJO, Antônio. A gênese da vertigem: o processo de criação de O Paraíso Perdido. São Paulo: Perspectiva/FAPESP, 2011. 
ARAÚJO, Antônio. Processo de criação do Teatro da Vertigem. Porto Alegre, 2012a. Palestra proferida no Programa de Pós-Graduação em Artes Cênicas da Universidade Federal do Rio Grande do Sul em 21 de junho de 2012.

DEBORD, Guy. A sociedade do espetáculo. Rio de Janeiro: Contraponto, 1997.

DEBORD, Guy. Por uma Internacional Situacionista: fragmentos do documento fundacional (1957). In: FELÍCIO, Erahsto (org.). Internacional situacionista: deriva, psicogeografia e urbanismo unitário. Porto Alegre: Deriva, 2007.

FELÍCIO, Erahsto (org.). Internacional situacionista: deriva, psicogeografia e urbanismo unitário. Porto Alegre: Deriva, 2007.

FÉRAL, Josette. O real na arte: a estética do choque. In: RAMOS, Luiz Fernando (org.). Arte e ciência: abismo de rosas. São Paulo: ABRACE, 2012. pp. 77-93.

FERNANDES, Sílvia. Teatralidades contemporâneas. São Paulo: Perspectiva, 2010.

INTERNACIONAL SITUACIONISTA. Definições Mínimas das Organizações Revolucionários (1967). Disponível em:

http://www.oocities.org/projetoperiferia5/is.htm. Acesso em 15 de outubro de 2012.

INTERNACIONAL SITUACIONISTA. Situacionista: teoria e prática da revolução. São Paulo: Conrad, 2002.

JAPPE, Anselm. Guy Debord. Petrópolis, RJ: Vozes, 1999.

RAMOS, Luiz Fernando (org.). Arte e ciência: abismo de rosas. São Paulo: ABRACE, 2012.

TEATRO DA VERTIGEM. Bom Retiro 958 metros. Espetáculo. Apresentações dos dias 27 e 28 de setembro de 2012. São Paulo, SP. 